\title{
Populus, demos and self-rule
}

\author{
David Owen
}

Rainer Bauböck's work on popular sovereignty, citizenship and the demos problem is an important touchstone for contemporary political, and especially democratic, theory. Grounded in attention to both the theoretical and empirical circumstances of individual and collective political agency, Bauböck offers a highly sophisticated and, in many ways, compelling approach to thinking through the philosophical and political challenges of citizenship and democracy in a global landscape characterized by a plurality of peoples, types of polity, multilevel governance and migration (internal and transnational). In this essay, I aim to put some pressure on the relationship between populus (i.e. the citizenry) and demos (i.e. those entitled, in one way or another, to participate in the decision-making process) in Bauböck's account. Put another way, I accept Bauböck's argument that the all citizenship stakeholders (ACS) principle is the best available principle for determining the composition of the citizenry but, in a particular and specific sense, reject the claim that it thereby also demarcates the demos.

\section{Demos principles and citizenship}

It is an important strength of Bauböck's argument that his account articulates complementary relations of the all affected interests (AAI) principle, the all subjection to coercion (ASC) principle and the all citizenship stakeholders principle. His position is summarized thus in 
section 3.4 of his essay. It is, however, an equally important feature of his argument that it draws attention to the normative political challenge that this argument poses for contemporary polities. In addressing Bauböck's argument, I will begin by developing the claim that ACS specifies who is entitled to be a part of the populus, a citizen of the polity, but not who is entitled to be a member of the demos. In this section, I advance this argument by distinguishing different types of membership of the demos and focusing on what I will call the authorial membership of the demos. In the following section, I argue that we have reason to distinguish between populus and authorial membership of the demos in addressing the issues identified by Bauböck and that doing so is normatively consequential for Bauböck's argument.

One way of thinking about the general structure of Bauböck's account and the differentiation of the three principles that he identifies as relevant to the demos problem is in terms of three distinct types of membership of the demos:

AAI demarcates the scope of discursive membership of the demos, that is, those entitled to voice or representation of their interests in the decision-making process.

ASC demarcates the range of editorial membership of the demos, that is, those entitled to contest the government's decisions.

ACS demarcates the limits of authorial membership of the demos, that is, those entitled to authorize the government's decisions.

However, if we compare this schema with Bauböck's own account, we find that rather than demarcating the scope of authorial membership of the demos, ACS identifies persons who have a legitimate claim to citizenship as membership in a self-ruling polity and, as Bauböck acknowledges, not all of those who satisfy ACS will be included in authorial membership of the demos. Specifically, Bauböck identifies two groups who he takes to be rightfully excluded from the franchise: persons who lack the capacity to vote or stand for election and persons who are stakeholders but whose stakes do not stand in the appropriate relationship to the polity. Let us address each in turn. 
Bauböck distinguishes between citizens included in, or excluded from, authorial membership of the demos in terms of their capacity to participate:

Even if the link between individual autonomy and collective selfgovernment need not imply that citizens have a duty to participate actively in the political life of the polity, it does imply that they must have the opportunity to do so. But this opportunity in turn depends on their capacity to participate. The citizenship status of minor children or cognitively disabled persons might then be in jeopardy under this conception whereas AAI and ASC would have no difficulty in arguing for their inclusion. (pp. 44-45)

He argues that, for example, if "there is no democratic way of providing children below a certain age with opportunities for participating in electoral politics" (pp. 45-46), they can be legitimately excluded. Why, then, should children, especially newborn or very young children, be included as citizens at all? After all, one way to identify the populus and authorial membership of the demos is to exclude children from citizenship until they meet the relevant capacity threshold. Bauböck's rejection of this seemingly theoretically neat solution is grounded in an appeal to "the conditions for continuity of a self-governing polity over time":

Newborn babies are attributed citizenship not just because we regard them as future citizens. If this were the case, one might as well wait until they have reached the age of majority and consider them until then subjects within the jurisdiction who have a claim to equal protection. The reason why we recognize them as citizens is that political communities are transgenerational human societies. The status of membership in such communities is acquired at birth and does not depend on agerelated cognitive or other capacities. In democracies, it is the larger transgenerational society that collectively governs itself and not the subcategory of adults who have the capacity and opportunity to vote or hold public office. Minor children are citizenship stakeholders because of their belonging to a transgenerational political community. (p. 46) 
However, this appeal to a transgenerational political community is, on Bauböck's own account, limited to some types of polity (e.g. states) and not others (e.g. municipalities). This point is reflected in the fact that ACS justifies birthright citizenship (supplemented by naturalization) for states, but residence-based citizenship for municipalities. Should children be citizens of states but not of municipalities? It is not clear why this should not be the case, especially as national citizenship would offer protection from domination for children who are citizens, while children who are not citizens would be entitled to editorial membership of the demos at both local and national levels. This criticism operates within the terms of Bauböck's argument, but we may also question these terms. There are two issues here. The first concerns where any capacity threshold should be drawn; the second whether a capacity threshold should be drawn.

On the first, it is notable that Bauböck appeals to the age of majority in relation to voting rights but no criteria for the identification of this age are offered. In principle, Bauböck could, I think, endorse the account of "franchise capacity" offered by Lopez-Guerra in which all who are capable of experiencing their exclusion from the franchise as an injustice ought to be enfranchised (Lopez-Guerra 2014: 71) rather than, say, a form of input minimalism which hangs on the epistemic claim to protect the quality of electoral outcomes (ibid.: 63-69). However, the significant issue is the second. Bauböck rightly holds that "giving parents proxy votes that they can cast on behalf of their minor children looks more like a violation of the one-person-one-vote principle in favour of a particular category of adults than a vehicle for children's participation in the polity" (p. 45), but this is hardly the only option. Consider an alternative in which all enfranchised persons also have a second "proxy" vote cast for candidates on a separate children's list who have a limited number of reserved seats in the legislature and whose role is to act as advocates for the interests of children and who have a qualified veto power (e.g. a power to refer back and require a supermajority for the bill to pass) over legislation that directly affects the interests of children as children. The inclusion of all voters acknowledges that the interests of children are not 
the sole domain of parents and that the vast majority of people stand in both general and agent-specific obligations of care towards children (e.g. older siblings, cousins, aunts and uncles, grandparents), while the limited number of reserved seats and particular powers provides conditions for the effective representation of the interests of children, not least since in each successive election a new group of voters who have been represented by these special representatives will be able to hold them to account for their performance. (One could experiment with weighting votes inversely to the number of elections since the voter acquired franchise rights, or would have done so if a citizen from the age of majority, so young voters' votes weigh more heavily than those of aged voters.) The point here is that it is not clear to me that Bauböck requires the appeal to transgenerational political community that would distinguish children's citizenship rights at national and municipal levels of governance; rather, he could tie citizenship to voting rights with a generalized distribution of "proxy" votes for children across the enfranchised citizenry. The political representation of the interests of children is a tricky political challenge but not obviously an insurmountable one - and while the case of children is, in certain respects, a special case among those excluded on capacity grounds, this does not entail that one could not develop related democratic proposals in other cases.

The second case is rather different. In his discussion of the problem of the over-inclusiveness of an unlimited ius sanguinis rule, Bauböck argues that third generation emigrants should not acquire citizenship at birth and continues:

It is more consistent with the birthright character of national citizenship to let it expire for the distant descendants of emigrants through non-acquisition at birth instead of depriving first or second generation holders of this status on grounds of long-term residence abroad and acquisition of a foreign citizenship. It seems, however, reasonable to exclude second generation emigrants who have never resided in the country from voting rights, even if they retain a lifelong citizenship status. Since voting rights are anyhow not acquired at birth but only 
around the age of majority, the concern about over-inclusiveness of an external franchise can be easily taken into account by tying the external franchise to a condition of prior long-term residence in the country; this would include not only first generation emigrants but also second generation returnees, while the children of emigrants who have never resided in the country would never acquire the franchise instead of being deprived of a birthright status. (pp. 69-70)

Apart from confirming Bauböck's appeal to the age of majority, this passage argues that the over-inclusiveness problem for an external franchise can be dealt with if the franchise is restricted to first generation emigrants and second generation returnees who have lived in the "home" state for some significant period prior to, respectively, emigration or re-emigration. There are two issues here. The first is that it is not clear what status Bauböck is ascribing to expatriate voting rights. The second concerns the non-identity of citizenship and authorial membership of the demos. I'll address these in turn.

In earlier work explicitly addressing the external franchise, Bauböck (2007) argues that expatriate voting is neither required nor forbidden by justice. Consider two sets of remarks. In the first, Bauböck reiterates the stakeholder principle:

The notion of stakeholding expresses, first, the idea that citizens have not merely fundamental interests in the outcomes of the political process, but a claim to be represented as participants in that process. Second, stakeholding serves as a criterion for assessing claims to membership and voting rights. Individuals whose circumstances of life link their future well-being to the flourishing of a particular polity should be recognized as stakeholders in that polity with a claim to participate in collective decision-making processes that shape the shared future of this political community. (ibid.: 2422)

This passage suggests that stakeholders have a legitimate claim to participate, although this does not rule out either that the reach of this claim (i.e. the extent of participation it legitimates) may vary or that it may be defeated by other legitimate concerns. In the second set of remarks, Bauböck comments: 
In a stakeholder conception of democratic community, persons with multiple stakes need multiple votes to control each of the governments whose decisions will affect their future as members of several demoi. This applies, on the one hand, to federally nested demoi where citizens can cast multiple vertical votes on several levels and, on the other hand, to the demoi of independent states with overlapping membership. (ibid.: 2428)

This gestures to a stronger view, namely that the stakeholder principle supports a requirement of inclusion in authorial membership of the demos for stakeholders, where we may surmise this requirement would be legitimately subject only to (a) the basic constraint that such inclusion does not threaten the stability of the state (i.e. its capacity to reproduce itself as a self-governing polity over time); and (b) feasibility constraints. Bauböck does not adopt this stance, remaining content with the view that expatriate voting is permissible but not required (although acknowledging the normative salience of existing state practices of expatriate enfranchisement as having constructed reasonable expectations which it would be unjust to frustrate given the normative permissibility of the practice). Overall, the most one can say is that, for Bauböck, the stakeholder principle broadly supports a presumption in favour of such rights for first generation migrants, while acknowledging that this presumption can be supported or defeated by a wide range of factors relating to the specific circumstances of the polity and the conditions that support its stable reproduction (Bauböck 2007).

The implication of this argument is that first and second generation emigrants are rightfully included in the citizenry but may be in the case of first generation emigrants and should be in the case of second generation emigrants excluded from the authorial membership of the demos. Recall that Bauböck also argues that third generation emigrants should be excluded from the citizenry:

It is obvious that third generation emigrants will generally not have a sufficiently strong stake in a grandparent's country of origin to claim citizenship, unless their parents have themselves renewed their links to this country through taking up residence there. In the case of second 
generation return ... the next generation of children born abroad are again second generation emigrants and qualify for citizenship based on their ties to parents who are themselves strongly linked to the country awarding the status. (p. 69)

The implication is that what legitimately includes second generation emigrants in the citizenry is that they do have a "sufficiently strong stake", but what legitimately excludes second generation emigrants from voting rights is that they don't have the same kind of stake as residents (or first generation emigrants). Recall at this point that the notion of stakeholding appeals to the relationship between individual autonomy and well-being on the one hand, and the collective autonomy and well-being of the polity on the other hand. ACS specifies that all whose autonomy and well-being are linked to the collective self-government and flourishing of a polity have a claim to citizenship. In this statement, stakeholding is being treated as a non-scalar property (i.e. what matters is being inside a given boundary, not how far inside you are). However, stakeholding can also be treated as a scalar property in which our concern is how much, how densely, how intensely, a person's autonomy and well-being are linked to the collective self-government and flourishing of a polity. This matters because it enables the setting of stakeholding thresholds internal to the general stakeholder boundary above which it will be treated in a non-scalar way - and this is what Bauböck is doing in restricting membership of the authorial demos to a subset of the general class of stakeholders. His explicit rationale for maintaining this exclusion claim runs thus:

Members of this so-called second immigrant generation still have a plausible interest in their parents' citizenship, and virtually all democratic countries therefore have external jus sanguinis provisions in their citizenship laws. Yet a right to acquire citizenship status at birth need not entail a right to vote. Benefits of external citizenship, such as diplomatic protection and the right to return to, and to inherit and own property in, the country of citizenship reflect interests of a slightly different kind than those that ground a right to political participation. The former 
refer to potential interests that a second generation external citizen may activate over the course of her life, whereas the latter should presuppose that some of these interests are currently active. (2007: 2426)

There are good reasons for advancing this distinction. For example, it is clear from the standpoint of a concern with individual autonomy that even though both resident and expatriate citizens are subject to the political authority of the state, the former are more comprehensively subject to the coercively enforceable authority of the state. Similarly, if we consider individual well-being it is entirely plausible that the well-being of resident citizens (and first generation emigrants whose identities were constituted through residence in the "home" state) is likely to be more densely dependent on the autonomy and well-being of the polity than the well-being of second generation emigrants. In this respect, the general notion of "stakeholding" is still playing the pivotal normative role but - and this is the point I would stress - ACS is now revealed as a principle for determining membership of the citizenry and not authorial membership of the demos. ACS is presented as a necessary but not sufficient condition of authorial membership of the demos.

At this stage in my argument, I need to introduce another set of distinctions in relationship to the concept of the demos. These relate to the kind of political decision-making in question (rather than the modes of relationship to decision-making that I have already distinguished in terms of discursive, editorial and authorial membership of the demos), and we can in general distinguish executive, legislative and constitutional demoi depending on the political system. ${ }^{1}$ For current purposes, it is the distinction between legislative and constitutional demoi that is pertinent. The salient normative difference between these demoi is that the judgements of the constitutional demos structure the fundamental terms of political association and, hence, the foundational commitments and character of citizenship as membership of the self-ruling polity,

1 We would also have to add "judicial" for polities in which judicial positions are subject to election. 
whereas the decision-making of the legislative demos addresses ways of structuring relationships between persons subject to the territorial jurisdiction and/or political authority of the state within the terms set by the constitutional rules and norms. This distinction matters for two reasons. First, it makes clear the priority of the constitutional demos for popular sovereignty, that is, for the people to be conceived as self-ruling. Second, even if there are legitimate reasons for some citizens - for example, second generation expatriate citizens - to be excluded from the legislative demos, these reasons do not apply to the constitutional demos since constitutional decisions are (a) collectively binding on all citizens and (b) constitutive of what, fundamentally, comprises one's political status as a citizen. For this reason, the authorial membership of the demos for constitutional decision-making should include all citizens regardless of their location.

Consider two examples. The first is the UK referendum on membership of the EU. Since the access to EU citizenship of UK citizens is derivative of their UK citizenship, this decision has clear and significant implications for the legal status of UK citizens living elsewhere in the EU but it also changes the legal position of UK citizens living outside of the EU. Even if we set this issue of legal status aside though, it fundamentally concerns the nature of the political association to which citizens belong and the terms on which they relate to one another and to others. This second point is clearly made by the second example, the 2004 Irish referendum on whether to abolish their unconditional ius soli rule in respect of citizenship acquisition. In this case, the proposed change would not have direct effect on the rights of any individual Irish citizens given that the existing ius sanguinis rule would be unaffected by such a change, but it would significantly change who had an automatic right to acquire Irish citizenship and hence the nature of the political association. In this respect, popular sovereignty requires that all citizens can express the judgement concerning this foundational aspect of Irish political community. These examples propose key test cases for Bauböck because if he holds that second generation immigrants can rightfully be excluded from authorial membership of the demos for 
constitutional decision-making, then he ought to exclude them from citizenship. (This would be compatible with giving them a distinct quasi-nationality status such as a right to accelerated naturalization conditional on a period of residence.) If, however, he wants to sustain their claim to citizenship, then he ought either to drop the claim to legitimate exclusion of second generation emigrants from voting rights or acknowledge that there is reason to distinguish the authorial composition of the constitutional demos and the legislative demos.

I think that the best option for Bauböck is to distinguish between the authorial composition of the constitutional demos and the legislative demos, not least because doing so would allow him to avoid a further problem to which his argument is otherwise subject. This problem is what elsewhere (Owen 2011) I have called the arbitrary demos problem and concerns the fact that if one holds the view, as Bauböck does, that expatriate voting rights in relation to legislative (or executive) elections are permissible rather than required or forbidden, one must still address the question of who is entitled to determine whether or not expatriates are included in the national franchise. To resolve it, what is required is a principled (i.e. non-arbitrary) basis on which to determine who is entitled to decide on this question. Here the fact there is one type of decision by any polity which not only binds all citizens irrespective of residence but also directly concerns their very status as citizens, namely constitutional laws that specify the entitlements and obligations of citizens - such as, for example, laws on nationality and expatriate voting rights - is critical. Moreover, because constitutional rules concern the character of citizenship itself, to deny any citizen or group of citizens the right to participate as an equal authorial member of the democratic community in the decision-making process is to deny their status as a citizen; it is to subject them to an alien form of rule. The only legitimate basis for such constitutional decisions as decisions on expatriate voting is, thus, that all citizens are entitled to authorial inclusion irrespective of their residential status (although this does not rule out that considerations of feasibility and cost may legitimately allow the requirement that votes are cast within the territory of the home state). 
If this is cogent, ACS not only demarcates those entitled to citizenship, but it also simultaneously identifies those who are entitled to authorial membership of the constitutional demos as the keystone of popular sovereignty. This may be compatible with the legitimate exclusion of some citizens from authorial membership of the demos for legislative (or executive) elections. Acknowledging this point, however, raises a further question. If legitimate inclusion in the citizenry is not a sufficient condition of authorial membership of the legislative demos, is it a necessary condition?

\section{Demos problems}

The argument thus far has involved what may appear to be a minor refiguring of Bauböck's account but, as this section will attempt to illustrate, the claims advanced provide the conceptual space to advance normative reasons that offer a significant challenge to Bauböck's argument. To begin to make this case, I shall return to his critical incorporation of AAI and ASC principles into the architecture of his account.

While rejecting AAI as a principle for demarcating the scope of authorial membership of the demos, Bauböck presents it as having a role to play in his overall account of democratic legitimacy as a principle addressed to policy decision-making:

Tracking affected interests requires taking these into account in decisionmaking, not after that decision has already been taken. Affected interests thus have a claim to be included in the process of deliberation that precedes the decision and not only the process of implementation that follows it. In other words, actually affected interests have a claim to voice. They must be heard and taken into account by those who take the decision. They form the relevant public for political decisions. Those whose interests are affected by democratic decisions, no matter whether they are citizens, subjects or completely outside the jurisdiction, have a right to justification of the decision that respects them as autonomous sources of valid claims. (p. 24) 
In my terms, Bauböck presents AAI as demarcating the scope of discursive membership of the demos. However, notice that, as Bauböck rightly states, this is not simply a right to speak but also a right to be listened to and have one's interests taken into account by authorial members of the demos. Put another way, for one's speech acts to be communicative acts within the discursive demos, the relevant conditions of deliberative uptake must be met. Since this cannot be presumed, the right to justification entails a right to contest decision-making that participants in the demos can reasonably take to have failed to meet the relevant conditions of deliberative uptake. Such an institutionalized right of contestation is practically necessary for assurance that deliberative process will give due regard to the interests of all affected non-resident non-citizens. What is contested here is not the outcomes of deliberation as such but rather the processes that gave rise to these outcomes. Internal to discursive membership of the demos, then, is a contestatory right. Another way to put this point is that discursive membership of the demos entails a particular process-focused form of editorial membership of the demos addressed to policy decision-making.

If we turn now to ASC, we can note that Bauböck's rejection of ASC as a principle for determining the authorial membership of the demos notes rightly that "it is systematically biased towards existing boundaries" (p. 29), before going on to advance the powerful challenge that ASC cannot account for the intuition that while it is legitimate for the U.S. to occupy Germany after World War II, it would have been entirely illegitimate for it to annex it. Or, again, in colonial contexts, it would have been entirely inadequate to respond to national liberation movements with the offer of equal citizenship in the imperium (as Bauböck's example of France and Algeria makes clear).

This argument strikes me as providing compelling reason for ASC to be rejected as the principle for determining claims to membership of the people who have a right to collective self-government in such contexts. This is why I endorse Bauböck's argument that ACS best identifies those who have a claim to membership of a self-governing people, a populus, and to citizenship in the polity that they (are entitled 
to) constitute. But notice that this is just to say that ACS appropriately identifies those who are entitled to authorial membership of the constitutional demos - it does not determine anything about authorial membership of the legislative demos. The rejection of ASC as a principle for determining membership of the populus does not entail its rejection as a principle for demarcating authorial membership of the legislative demos - and there are compelling reasons why we may wish to adopt it for this role.

Consider the classic argument provided by Robert Dahl for the "Principle of Full Inclusion" which can be stated thus: "The demos must include all adult members of the association except transients and persons proved to be mentally defective" (1989: 129), where "adult members of the association" refers to "all adults subject to the binding collective decisions of the association" (ibid.: 120). As Lopez-Guerra helpfully notes, Dahl's specification of criteria of democracy can be summarized thus:

(1) governments must give equal consideration to the good and interests of every person bound by their laws (principle of intrinsic equality); (2) unless there is compelling evidence to the contrary, every person should be considered to be the best judge of his or her own good and interests (presumption of personal autonomy); therefore (3) all adults [who are not merely transients (1) and are not shown to be mentally defective (2)] should be assumed to be sufficiently well-qualified to participate in the collective decision-making processes of the polity (strong principle of equality). (Lopez-Guerra 2005: 219, my insertion)

In the context of a territorial state, Dahl's account implies that any competent adult who is habitually resident within the territory of the state and, hence, subject to the collectively binding laws and policies of its government is entitled to full inclusion within the demos. ${ }^{2}$ Such

2 Although Dahl talks of the Principle of All Affected Interests, I agree with Lopez-Guerra (2005: 222-225) that since it is being governed that is the normatively relevant issue for Dahl, the relevant principle is that of being subjected to rule rather than affected by rule. For defences of the all affected principle, see Shapiro (2003) and Goodin (2007). 
an argument can be taken to underwrite Walzer's claim that the denial of full political rights to habitual residents amounts to citizen tyranny (Walzer 1983: 55). ${ }^{3}$

Dahl's argument is built in two stages. The first stage offers reasons for supporting the Strong Principle of Equality and hence democracy against other forms of rule; the second stage moves from this principle to the Principle of Full Inclusion as a way of specifying the composition of the demos. The Strong Principle of Equality can be stated thus:

All members are sufficiently well-qualified, taken all around, to participate in making the collective decisions binding on the association that significantly affect their good or interests. In any case, none are so definitely better qualified than the others that they should be entrusted with making the collective and binding decisions. (Dahl 1989: 98)

To ground this principle, Dahl appeals to two further claims. First, the Principle of Intrinsic Equality expresses the claim that governments must give equal consideration to the good and interests of every person subject to their laws. This principle is not itself sufficient to ground the claim to democratic government expressed in the Strong Principle of Equality since it does not entail that equal consideration is best or only realized through democratic rule. Hence Dahl introduces a second claim, the Presumption of Personal Autonomy, which states: "In the absence of a compelling showing to the contrary everyone should be assumed to be the best judge of his or her own good or interests" (ibid.: 100). Whereas the Principle of Intrinsic Equality is a universal moral claim that expresses the claim to equal treatment of all those subject to a scheme of rule and hence their fundamental interest in being treated as an equal, the Presumption of Personal Autonomy is a prudential claim. As Dahl notes:

Walzer links this claim to one in which the polity has the right to determine its own entry criteria as an element of its right to self-determination; for an excellent analysis of the difficulties that this conjunction generates, see Bosniak (2006). 
To reject it as a presumption for individual and collective decisions, however, we would have to believe not only that (1) some substantial portion of adults are quite unable to understand, or are not sufficiently motivated to seek, their most fundamental interests, but also that (2) a class of paternalist authorities could be counted on to do so in their behalf. (Ibid.: 101)

Dahl reasonably appeals to our political history to indicate that we can have little confidence in (2), but we can helpfully develop the grounds of this prudential claim by drawing on arguments proposed by Cristiano in response to this question of whether my fundamental interest in being treated as an equal may be better advanced if those more enlightened than I have the power to determine laws and policies under which I should live. As Cristiano comments:

The epistemic access that each person has to her own interests and the cognitive biases that interfere with their understanding of others' interests (along with the idea that equality involves advancing those interests) suggest that the epistemic differences between persons on these matters is not likely to be very great and that a person's interests will be neglected if they do not participate ... And, of course, there is always a lot of disagreement among even the enlightened about what equality and interests require. (2015: 248)

On the basis of this argument, Cristiano notes that "given the setback of these fundamental interests [through exclusion from the demos], each person whose interests are set back in this way will have reason to think that she is not being treated as an equal" and, since each person has a fundamental interest in being recognized as an equal whose interests count equally with others', this interest "cannot be met if this person lives in a world that can be seen by others to be treating them as equals but which she cannot see to be treating her as an equal" (ibid.: 248). Cristiano's argument thus helps to clarify further how the relationship between the Principle of Intrinsic Equality and the Presumption of Personal Autonomy suffice to ground the Strong Principle of Equality. 
The next step is to note that we require criteria to determine who has a rightful claim to membership of the demos in order to draw normatively salient distinctions between democratic states and states which restrict membership of the demos to any particular group (e.g. white men). In the light of the foregoing arguments, one attractivelooking response to this requirement is to offer a categorical principle according to which everyone subject to a government and its laws has an unqualified right to membership of the demos (Dahl 1989: 124). Dahl's objection to this categorical principle is that it elides the problem posed by competency issues. Although he acknowledges that criteria of competency are defeasible, Dahl, like Bauböck, holds that in the case of young children and the severely cognitively disabled who are unable to meet the minimal criteria required for personal autonomy (i.e. pursuing, revising or rejecting conceptions of the good or seeking their fundamental interests), exclusion from the demos is justified. ${ }^{4}$ It is notable that it is in his discussion of competency issues that Dahl also addresses the exclusion of transients:

Suppose France is holding an election on Sunday and I, an American, arrive in Paris on Saturday as a tourist. Would anyone argue that I should be entitled to participate in the election, much less acquire all the other political rights of French citizenship? I think not. On what grounds could I properly be excluded? On the grounds that I am unqualified. (Ibid.: 128)

This is a problematic argument, however, as Dahl comes to recognize. Suppose I can demonstrate that, having studied French politics, I am fully aware of the issues: then the objection that matters is not that I am unqualified but rather that, as a transient visitor to the state, I may not be subject to the laws that my participation helps to bring about.

4 I referred earlier to Lopez-Guerra (2014: 71), who has advanced an argument that we can relate to Dahl's and Cristiano's argument by drawing attention to the fact that denial of franchise to a person is susceptible of producing injustice. Lopez-Guerra's suggestion is that only habitual residents who are incapable of experiencing disenfranchisement as an injustice in these senses can legitimately be excluded from the franchise. 
If I had voting rights, I would be involved in authoring collectively binding decisions to which, presumptively, I would not be subject (ibid.: $354-355$, n. 11) There are thus two legitimate forms of exclusion from the demos on Dahl's account: first, exclusion on incompetency grounds and, second, exclusion on "presumptive non-subjection" grounds. It is the combination of these considerations that leads Dahl to reject categorical principles of inclusion in favour of the conditional principle that he terms "the Principle of Full Inclusion".

This type of general argument concerning democracy as a form of rule provides prima facie reason for the inclusion of all non-transitory residents in the legislative demos. However, Bauböck can respond that when democratic rule is mediated through the political form of the state, the implication of this argument is that non-transitory residents should be entitled to citizenship and ACS acknowledges this claim. The key issue here is that whereas ASC simply requires that non-transitory residents be enfranchised, ACS requires that they be granted access to citizenship. It is certainly an advantage of ACS that it has this entailment; however, our question is whether this legitimates the exclusion of non-transitory residents who choose not to acquire citizenship from the legislative demos. ${ }^{5}$

The claim that such exclusion is illegitimate has been acutely put by Angeli's discussion of the condition of a resident non-citizen. Angeli's argument has two elements. The first draws attention to the fact that, in the conduct of her life, the resident non-citizen is required to navigate

a dense and complex network of legal norms that is "backed up by coercive measures that implicate the liberal principle of autonomy". Her profession, her private aspirations and other dimensions of her life are "matters that the legal system influences at every turn - by recognizing

Two alternative views are available. The first denies that non-transitory residents should be entitled to choice, arguing that citizenship should be mandatory (Rubio-Marin 2000). The second acknowledges Bauböck's argument for the choice to naturalize being voluntary but draws a distinction between citizenship and membership of the legislative demos and argues that the latter should be mandatory (Owen 2011). Here I focus only on the second. 
(or not) different rights and liberties, by carving out specific rules of property and contract, and so on.”... [In] a territorially organized legal system coercive constraints are virtually omnipresent in the life of resident people. And it is precisely the density and pervasiveness of coercion that causes liberal political theorists to worry about the extent to which residents are capable of leading an autonomous life and not a life according to other people's understanding of what is valuable and worth doing. (2015: 89)

We can link this argument back to Dahl's and Cristiano's argument that the denial of rights of membership of the legislative demos will almost inevitably lead to one's life being shaped and constrained by "other people's understanding of what is valuable and worth doing" even if they are making good faith efforts to acknowledge one's own interests. Angeli's second step is to note that this is particularly problematic in respect of coercive laws and policies over which there is widespread disagreement. Thus, whereas an important range of laws - such as those protecting basic human rights or establishing neutral conventions for the coordination of basic activities (driving on the left or right, for example) - command widespread agreement among the inhabitants of democratic states, much else is subject to significant degrees of substantive moral and political disagreement. Hence, Angeli argues: "When disagreements about the legitimacy of coercive measures occur, democratic processes provide a solution. These processes offer the potential for residents to express their wills on roughly equal terms and to accord each other's views and interests respect" (ibid.: 90).

Granting all residents the right to participate in democratic practices and institutions involves recognizing that these kinds of disagreements over the legitimacy of coercive laws must be settled by those who are subject to them.

It may be objected that this undermines the self-rule of the national citizenry, but there are two responses to this objection. The first is that the fundamental condition of self-rule is met by the fact that authorial membership of the constitutional demos is reserved for citizens. The 
second is that, on Bauböck's own account, the democratic legitimacy of popular self-rule requires that laws and policies track the common good of all subjected to them - and, as the above arguments show, determining and tracking the common good requires the inclusion of resident non-citizens as authorial members in the legislative demos. Does this undermine the transgenerational political community by weakening incentives for resident non-citizens to naturalize? We might say, rather, that it supports the conditions of genuine consent by weakening an instrumental reason for resident non-citizens to naturalize.

\section{Conclusion}

In this essay I have endorsed Bauböck's proposal of ASC as the best principle, under contemporary political conditions, for determining access to national citizenship. I also welcome his incorporation of AAI, ASC and ACS into an account of democratic legitimacy - a move that significantly advances the debate concerning political membership and the demos problem in contemporary political theory. My critical aim has been to argue that ACS in determining who is entitled to citizenship and, hence, to authorial membership of the constitutional demos does not thereby determine who is entitled to authorial membership of the legislative demos and that we have good reason to endorse ASC as the appropriate principle for playing this role. I have also shown that this has practical implications. In contrast to Bauböck's account, all nonresident citizens have a claim to be included in constitutional referendums and all long-term resident non-citizens have a claim to be enfranchised in national elections.

\section{References}

Angeli, Oliviero 2015. Cosmopolitanism, Self-determination and Territory. Basingstoke: Palgrave. 
Bauböck, Rainer 2007. "Stakeholder Citizenship and Transnational Political Participation." Fordham Law Review 75 (5): 2393-2447.

Bosniak, Linda 2006. The Citizen and the Alien. Princeton: Princeton University Press.

Cristiano, Thomas 2015. The Constitution of Equality. Oxford: Oxford University Press.

Dahl, Robert 1989. Democracy and Its Critics. New Haven: Yale University Press.

Goodin, Robert 2007. "Enfranchising All Affected Interests and Its Alternatives." Philosophy and Public Affairs 39 (1): 40-67.

Lopez-Guerra, Claudio 2005. "Should Expatriates Vote?" Journal of Political Philosophy 13 (2): 216-234.

Lopez-Guerra, Claudio 2014. Democracy and Disenfranchisement. Oxford: Oxford University Press.

Owen, David 2011. "Transnational Citizenship and the Democratic State." Critical Review in Social and Political Philosophy 14 (5): 641-663.

Rubio-Marin, Ruth 2000. Immigration as a Democratic Challenge. Cambridge: Cambridge University Press.

Shapiro, Ian 2003. The Moral Foundations of Politics. New Haven: Yale University Press.

Walzer, Michael 1983. Spheres of Justice. New York: Basic Books. 